Tjalling C. Koopmans Research Institute Tplligh Aoopman

Discussion Paper Series nr: 04-17

\title{
The Filtering Effect of Sharing Rules
}

Giuseppe Dari Mattiacci

Gerrit de Geest 


\section{Tjalling C. Koopmans Research Institute Utrecht School of Economics \\ Utrecht University}

Vredenburg 138

3511 BG Utrecht

The Netherlands

telephone $\quad+31302539800$

fax $\quad+31302537373$

website www.koopmansinstitute.uu.nl

The Tjalling C. Koopmans Institute is the research institute and research school of Utrecht School of Economics.

It was founded in 2003, and named after Professor Tjalling C. Koopmans, Dutch-born Nobel Prize laureate in economics of 1975.

In the discussion papers series the Koopmans Institute publishes results of ongoing research for early dissemination of research results, and to enhance discussion with colleagues.

Please send any comments and suggestions on the Koopmans institute, or this series to M.vanDort@econ.uu.nl

ontwerp voorblad: WRIK Utrecht

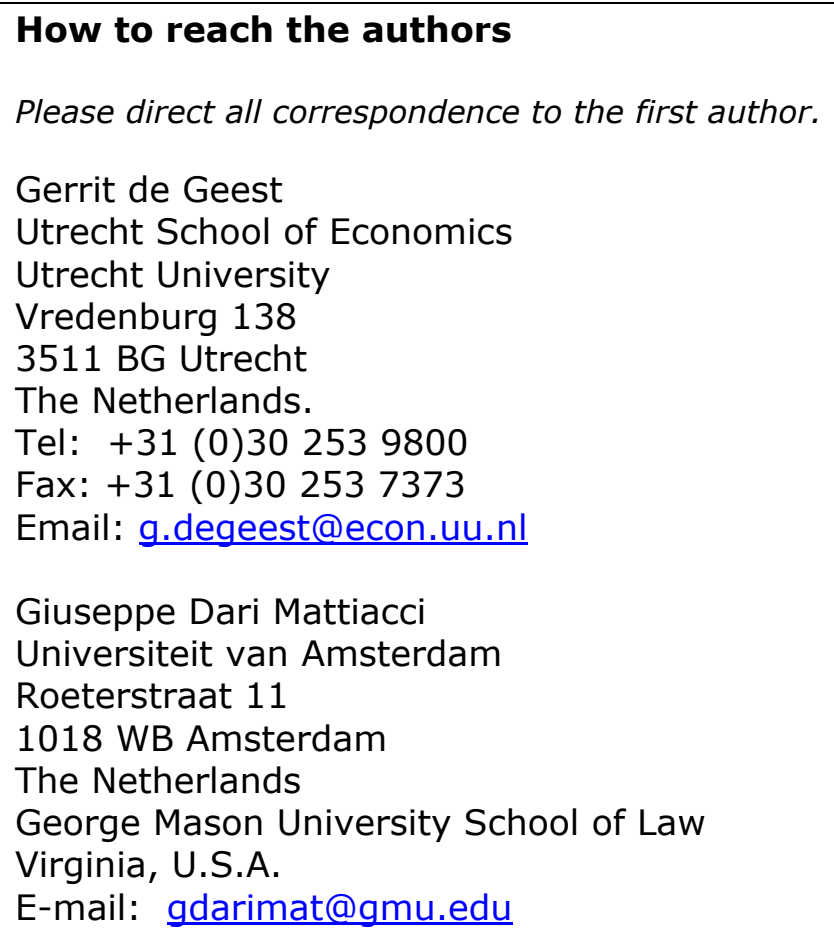




\title{
The Filtering Effect of Sharing Rules
}

\author{
Giuseppe Dari Mattiaccia b \\ Gerrit de Geest ${ }^{c}$ \\ aUniversity of Amsterdam \\ ${ }^{b}$ George Mason University of Law \\ U.S.A. \\ ${ }^{\mathrm{c}}$ Utrecht School of Economics \\ Utrecht University
}

July 2004

\begin{abstract}
Sharing rules have a filtering effect on violations: they prevent the most harmful violations and let the least harmful ones occur. We show under what conditions the filtering effect improves social welfare and argue that this may explain why, in most areas of the law, sharing rules are, in general, preferred to rules that entirely burden one party. Our analysis applies to comparative negligence, communal liability, the allocation of police investigation efforts, contract remedies for non-verifiable breaches such as those that may occur in marriage and employment contracts, and to the distribution of shares in partnerships.
\end{abstract}

Keywords: comparative negligence, law enforcement, divorce, employment contracts, theory of the firm.

\section{JEL classification: $\mathrm{K} 13$}

\section{Acknowledgements}

We would like to thank Hans Bern Schäfer, Winand Emons, Carlo Ferrigno, Jana McLean, Ben van Velthoven, the participants in the $17^{\text {th }}$ annual conference of the European Association of Law and Economics, Ghent (2000), and in the annual meeting of the Italian Economists Society, Rome (2001), for helpful comments on a previous draft of this article, circulated as "Comparative Negligence as a Filter Mechanism When Courts Cannot Observe Precaution Costs", written when both of us were at Utrecht University. We are also grateful to Bruno Lovat and an anonymous referee who generously provided us with key indications on how to improve the core of the analysis. Devlin Cooper and Andrea Naylor provided valuable editorial assistance. 


\section{Introduction}

Sharing rules are endorsed in law but distrusted in academia. One of the most troubling perplexities - but not the sole - arises from comparative negligence in tort. Although this is the most common liability rule across legal systems, the puzzle of its wide use is still to be resolved, and most previous explanations have been rebuffed in a recent article. ${ }^{1}$ Other rules that allow for implicit loss sharing, such as no-fault divorce systems and the employment-at-will doctrine, are also fiercely debated in the literature. ${ }^{2}$

In this article, we show that sharing rules have a filtering property that may advance social welfare because they stop the most harmful violations while letting the least harmful occur.

To illustrate, suppose that an accident could have been avoided if either the victim or the injurer had taken precaution. Ex post, the court cannot determine which party could have taken precaution and only knows that the probability that injurers are avoiders is $60 \%$, while it is $40 \%$ for victims. Assume further that the harm is $\$ 100$, and the avoider's precaution may cost either $\$ 30$ or $\$ 70$.

An all-or-nothing rule which fully targets the injurer (such as strict liability), maximizes the ex ante probability of avoiding the accident, and in fact prevents $60 \%$ of the accidents (all those in which the injurer is the avoider). If the court instead shares the loss among the parties (60\% to the injurer and $40 \%$ to the victim), then the avoider will prevent the accident when his precaution costs less than his share in the harm (\$30), and will let the accident occur when precaution costs more (\$70). In this case, there are more accidents. In fact, the injurer will prevent the accident in only half of the cases in which he is the avoider $(60 \% / 2)$ and the victim will do likewise $(40 \% / 2)$. Thus, only $50 \%$ (instead of $60 \%$ ) of the accidents will be prevented.

Nevertheless, the net social cost is lower than before. In fact, if precaution costs are high $(\$ 70)$, then the net social cost of letting an accident occur is low $(\$ 100-\$ 70=\$ 30)$. On the contrary, if precaution costs are low $(\$ 30)$, the net social cost is high $(\$ 100-\$ 30=\$ 70)$. Under an all-or-nothing rule, accidents take place without any selection and their expected net social cost is $60 \%$ times the average net cost of an accident $(\$ 30+\$ 70) / 2$, that is, the expected net social cost is equal to $\$ 30$.

Quite the reverse, the accidents that take place under a sharing rule are only those that cost $\$ 70$

\footnotetext{
${ }^{1}$ See Bar-Gill and Ben-Shahar (2003).

2 That no-fault divorce systems and employment-at-will contracts have an implicit loss-sharing function is explained in section 5. Dnes' (2000) review of the literature on marriage contracts is highly critical of no-fault divorce systems. The original justification of the employment-at-will doctrine by Epstein (1984) has been criticized in several studies. See Buechtemann and Walwei (1999).
} 
to prevent and hence yield a net social cost of only $\$ 30$. Since only $50 \%$ of the accidents occur, sharing rules yield an expected net social cost equal to only $\$ 15$. Thus, sharing yields a lower social cost than the all-or-nothing approach.

This example illustrates the main two points that we will elaborate upon in the next sections. First, the filtering effect of sharing rules generally improves social welfare, because focusing the incentive on those violations that yield a higher social cost ultimately reduces the cost borne by society. Second, this reduction in the social cost may be accompanied by an increase in the probability of violations. In fact, as it is obvious, if the goal of law enforcement is to reduce the number of violations, then incentives should be focused entirely on the party that is most likely to violate the rule. As the example shows, however, this policy may reduce social welfare instead of enhancing it.

The optimal sharing will be shown to depend on three variables: the type of accident context, the information available to the judge, and the distribution of the parties' costs of precaution.

In unilateral-care cases - that is, when only one party is able to avoid the accident at reasonable costs - we show that there always exists some sharing that dominates all-or-nothing rules for any distribution of the precaution costs. We also show that, if the distribution is symmetric, the optimal share of a party is equal to that party's probability of being the avoider. This rule is very easy to apply since it requires no complex calculation and is valid for a broad class of distributions, which include, among others, the plausibly very common cases of uniform distributions and random distributions.

If the judge has no information on the distribution function, then it is plausible to attribute the same probability to each cost, that is, to assume that the parties' precaution costs are distributed according to a uniform distribution ${ }^{3}$ and hence that, as we have just noticed, the optimal sharing for each party is equal to the probability of being the avoider. If this probability is also unknown, then an equal sharing is evidently desirable.

In alternative-care cases - that is, when both parties can avoid the accident at reasonable costs but, again, one party's precaution is sufficient to prevent it - sharing is affected by a free-riding problem, as the parties tend to externalize the cost of precaution on each other. We show under what conditions this problem disappears and sharing is still superior to all-or-nothing rules. Also in this case, we devote particular attention to the uniform-distribution case and in general to symmetric distributions and show that equal sharing has some advantages both in terms of social welfare and its easiness to apply.

In a nutshell, we argue that if courts know the distribution of the parties' precaution costs, an

\footnotetext{
${ }^{3}$ On this point see Savage (1954) and Mas-Colell, Whinston, and Green (1995, pp. 205 ff.).
} 
optimal sharing can be found that is better for social welfare than all-or-nothing rules. If courts do not know the distribution, then sharing according to the probability of guilt is optimal. If this bit of information is also missing, sharing equally is optimal.

This article is structured as follows. Section 2 provides an overview of the intellectual taste and distaste for sharing in the economic literature. Section 3 develops the first part of our formal analysis, presenting the model of unilateral care. Section 4 contains the model of alternative care. Section 5 discusses several applications of our analysis and concludes.

\section{The (dis)taste for sharing}

While sharing rules are largely used in different areas of law, the economic literature has mainly ${ }^{4}$ focused on the relatively recent rise of comparative negligence in tort. ${ }^{5}$ The efficiency reasons for such a rise are, however, intensely debated. The opinion of early writers about the efficiency of comparative negligence was largely negative. ${ }^{6}$ Later scholarship proved a now generally accepted efficiency-equivalence theorem, which states that all negligence rules provide, in principle, equivalent incentives to take optimal care. ${ }^{7}$ Comparative negligence, however, is believed to generate higher administrative costs than its all-or-nothing alternatives ${ }^{8}$ and, thus, its pervasive diffusion is puzzling.

The efficiency equivalence theorem is based on a number of assumptions, including that courts operate under perfect information and that due care is set at the optimal level. Therefore, many authors have tried to develop economic arguments for comparative negligence by relaxing some of these assumptions. When there is evidentiary uncertainty, ${ }^{9}$ parties might take an inefficient level of precaution in order to minimize their expected liability. It has been argued that comparative negligence, by distributing the loss between the parties, reduces the effect of errors and results in

\footnotetext{
${ }^{4}$ For a discussion of the literature on (implicit) sharing rules in other areas of tort law, law enforcement, and in marriage law and employment regulation we refer to section 5.

${ }^{5}$ See Curran (1992), Restatement (Third) of Torts: Products Liability sec. 17 (1998), and Restatement (Third) of Torts: Apportionment of Liability (1999) for a perspective on American law.

${ }^{6}$ See Brown (1973), Green, (1976, p. 558), and Diamond (1974a, pp. 140-145). Those studies, however, did not consider that the sharing of the loss under comparative negligence is connected with the implementation of a standard of care, and thus, the loss is shared only if both parties are found negligent. On the first formal approaches to tort liability see also Diamond (1974b) and Diamond and Mirrlees (1975).

${ }^{7}$ According to the efficiency-equivalence theorem, all negligence rules (simple negligence, contributory negligence and comparative negligence) lead to optimal incentives if the due level of precaution is correctly defined. Landes and Posner (1980) proved this result. See also Haddock and Curran (1985). For a survey see Schäfer and Schönenberger (2000, pp. 608-610).

${ }^{8}$ Low and Smith (1995) contend that comparative negligence gives more incentives to sue and to hire attorneys than allor-nothing rules. White's (1989) empirical study suggests that comparative negligence gives parties weaker incentives to take precaution than contributory negligence.

${ }^{9}$ Evidentiary uncertainty occurs when the courts make random errors in comparing the due level of precaution to the level of precaution actually taken by the parties or when judges err with respect to the precaution costs actually borne by the parties. See Cooter and Ulen (1986) for the former situation and Haddock and Curran (1985) for the latter.
} 
less distortion. ${ }^{10}$ Comparative negligence has also been defended when the due level of precaution is uniform for all parties but the individual costs of precaution $\operatorname{differ}^{11}$ and when parties make precaution decisions sequentially. ${ }^{12}$ In these cases, comparative negligence has been said to have a screening effect on the parties. A recent survey article casts serious doubts on the validity of any previous case for comparative negligence. In particular, it is shown that distributing the loss between the parties does not always improve social welfare under evidentiary uncertainty and that simple and contributory negligence may also have screening properties. ${ }^{13}$ Consequently, the case for or against comparative negligence is once again reopened.

Our analysis belongs to the set of contributions that attempt to provide a justification for comparative negligence on the basis of informational shortfalls of the judicial system, but it is different from previous contributions in several respects. Previous studies deal with situations in which both parties need to take precaution in order for the accident to be avoided. ${ }^{14}$ Instead, we focus on situations in which one party's precaution is sufficient to prevent the accident. The rule we study is not, therefore, the traditional form of comparative negligence under which the loss is shared between negligent parties. In fact, since only one party needs to take precaution, it can never occur that both are negligent. Instead, sharing takes place in our framework when it is not possible to single out the only negligent party. ${ }^{15}$

\footnotetext{
${ }^{10}$ Edlin (1994) argued instead that in these situations comparative and contributory negligence only differ with respect to the standard of negligence that is to be implemented for an efficient outcome to result. Shavell (1987) showed that comparative negligence could be superior in non-equilibrium situations, when (for some reasons) victims or injurers are found negligent. See also Orr (1991) and Chung's (1993) related comment.

${ }^{11}$ See Rubinfeld (1987). See also the analysis on accidents when parties are not identical by Emons (1990a and 1990b) and Emons and Sobel (1991).

${ }^{12}$ In this case, one party can observe the other party's level of precaution before choosing his. See Rea (1987) and Grady (1990).

${ }^{13}$ Bar-Gill and Ben-Shahar (2003) have reexamined the literature on the topic, though they did not touch upon all studies mentioned in this section. They first analyze contributions based on evidentiary uncertainty. The common tenet of these contributions is that all-or-nothing rules severely distort one party's precaution decision, while comparative negligence creates two smaller distortions for both parties. These arguments are shown to be grounded on the wrong belief that two small distortions have less consequences on social welfare than one greater distortion. The authors disprove this contention by showing that the comparative negligence rule does not generally induce the most symmetric distortions and that, in any case, two small distortions are not necessarily preferable to a single greater one in terms of resulting social welfare. Further, they examine arguments based on the contention that comparative negligence works as a screening mechanism when parties' different costs of care are undistinguishable by the courts. In this case, the counterargument is that all liability rules have screening properties, which may or may not enhance social welfare. Thus, screening does not provide a general case for comparative negligence

${ }^{14}$ Bar-Gill and Ben-Shahar (2003, p. 438) limit their analysis to bilateral precaution situations. In our framework, the case of joint care would be uninteresting as it is obvious that under all-or-nothing rules all accidents would occur, while sharing rules would at least prevent some of them.

${ }^{15}$ Although the filtering effect may be seen as a form of screening mechanism, it does not operate through the setting of a negligence standard but purely through the sharing of the accident loss. For this reason, filtering is only proper of sharing rules and is absent in all-or-nothing rules. Thus, the claim that all negligence-based liability rules have screening properties (as they all apply a standard of due care) cannot be extended to filtering. Filtering occurs in situations that are close to evidentiary uncertainty. However, in all cases belonging to this group, the standard of care is erroneously applied with some positive probability. In our framework, there is no standard to apply and the judge is completely blind with respect to identifying the avoider.
} 


\section{The model of unilateral care}

We consider a simple model with two risk-neutral, utility-maximizing parties who are strangers to each other. Only one of them may take precaution at a reasonable cost (a cost that is less than or equal to the harm) in order to prevent ${ }^{16}$ the accident: ${ }^{17}$ we call this party the avoider. ${ }^{18}$ The other party is passive. ${ }^{19}$ The avoider may be of various types, depending on his precaution cost. Ex post, it is not possible to determine which party was the avoider, but the probability that either party is the avoider is known. A legal rule determines ex ante the shares of each party in the harm. Let:

$$
\begin{aligned}
h= & \text { the harm, } h>0 ; \\
c= & \text { the avoider type (that is, the avoider's cost of precaution), } 0 \leq c \leq h ; c \text { is distributed } \\
& \text { according to a density function } f(c) \text { and a cumulative distribution } F(c) \text {; with } f(c) \\
& \text { continuously differentiable over } 0 \leq c \leq h, \text { positive over the same interval and zero } \\
& \text { elsewhere, } F(0)=0 \text { and } F(h)=1 ; \\
\pi= & \text { the probability that party } 1 \text { is the avoider, } 0<\pi<1 ; \\
\sigma= & \text { party 1's share in the harm, } 0 \leq \sigma \leq 1 .
\end{aligned}
$$
according to a density function $f(c)$ and a cumulative distribution $F(c)$; with $f(c)$ continuously differentiable over $0 \leq c \leq h$, positive over the same interval and zero

Let a sharing rule be a rule that implements $0<\sigma<1$, and let an all-or-nothing rule be a rule that implements $\sigma=0$ or $\sigma=1$. The avoider knows the legal rule before he decides whether to take precaution. The net social cost function $S$ is defined as the difference between the harm and the avoider's cost of precaution if no precaution is taken (and an accident occurs). $S$ is zero otherwise. ${ }^{20}$ Avoiders will take precaution if the cost of precaution is less than or equal to their share in the harm. Therefore, the ex ante net social cost resulting from a rule that shares the harm ex post

\footnotetext{
${ }^{16}$ Our model is based on a binary decision on whether or not to take precaution, and it is, in this respect, similar to the standard models used for law enforcement. In tort law and economics, instead, models usually (but not always) describe precaution as a continuous variable. Thus, our model directly applies to those cases in which precaution involves a binary decision and only approximates those in which there are multiple levels of precaution to be taken into account. Examples of the former types of situations are not driving through a red light, yielding for pedestrians, adopting a new pollutioncontrol technology in a chemical plant, installing a navigation devise on a boat, and so forth.

${ }^{17}$ We are assuming that, if precaution is taken, no accident occurs and that, conversely, if no precaution is taken an accident occurs. Considering accidents that only occur with a certain probability less than 1 if no precaution is taken or accidents that occur with a certain positive probability even if precaution is taken would not change the substance of our arguments or the results of our model given that the choice of whether or not to take precaution is assumed to be binary and parties are assumed to be risk neutral.

${ }^{18}$ Note that the avoider is not necessarily the injurer. The problem courts face in the case under examination is indeed the identification of the avoider between the victim and the injurer. Note also that our model is not restricted to unilateral-risk cases, in which only the victim suffers harm. Quite the opposite, the model allows for both parties to be affected by the accident. We consider the total loss arising from the accident and ask who should bear it, irrespective of where the loss originally fell.

${ }^{19}$ In our model we do not consider possible distortions in the levels of the parties' activities due to the fact that the party who is 'innocent' is sometimes sanctioned.

${ }^{20}$ Note that this formulation is equivalent to saying that the social cost is equal to either the harm or the precaution cost, given that if precaution is taken there is no harm. The net social cost is simply the difference between the social cost so calculated and the ideal case in which precaution is taken in each individual case. We adopt the latter perspective for
} 
according to $\sigma$ can be calculated as the weighed sum of the net costs of each parties' non-prevented accidents:

$$
S(\sigma)=\pi \int_{\sigma h}^{h} f(c)(h-c) d c+(1-\pi) \int_{(1-\sigma) h}^{h} f(c)(h-c) d c
$$

Likewise, the expected probability of an accident actually occurring is:

$$
P(\sigma)=\pi[1-F(\sigma h)]+(1-\pi)[1-F((1-\sigma) h)]
$$

Figure 1 depicts the avoider type on the vertical axis and its cumulative distribution on the horizontal axis. The social cost is the sum of the two shaded areas weighed by the probabilities $\pi$ and $1-\pi$. The probability of an accident is instead the sum of the projections of these areas on the horizontal axis weighed by the same probabilities.

Observation 1. Sharing rules always filter out the relatively most harmful accidents; all-or-nothing rules do not have such a filtering effect.

The relative harmfulness of accidents is given by their net social cost. In our model, the harm is constant; ${ }^{21}$ hence, accidents with a lower cost of precaution are the relatively most harmful ones. If $\sigma=0$, party 2 is always incentivized, while party 1 will never take precaution. Hence the social cost under such an all-or-nothing rule is:

$$
S(0)=\pi \int_{0}^{h} f(c)(h-c) d c
$$

The argument we are making holds symmetrically for $\sigma=1$. By looking at the lower and the upper boundary of the integral in Exp. (3) - which is calculated on the interval from 0 to $h$ - it is easy to see that in this case a fraction $\pi$ of the accidents occur, irrespective of their harmfulness. In contrast, under the sharing rule in Exp. (1), the most harmful accidents are prevented - precisely those whose cost of precaution is less than the party's share in the harm - since the integrals are calculated on the interval from $\sigma h$ and $(1-\sigma) h$, respectively, to $h$.

The same observation can be made by looking at figure 1 and noticing that the most harmful accidents are those to the left of the figure, for which the cost of precaution is relatively low if compared to the harm.

convenience.

${ }^{21}$ Changing this assumption would not, however, impair the results we derive. 


\section{[figure 1]}

The filtering effect due to sharing enhances social welfare, as it reduces the cost borne in the aggregate by society. Therefore, as the next proposition shows, sharing rules are superior to all-ornothing rules.

Proposition 1. In unilateral-care cases, there always exists some sharing that yields a lower social loss than all-or-nothing rules.

Proof. The first derivative of Exp. (1) yields:

$$
S^{\prime}(\sigma)=-\pi f(\sigma h)(1-\sigma) h^{2}+(1-\pi) f((1-\sigma) h) \sigma h^{2}
$$

The interpretation of Exp. (4) is straightforward: an increase in $\sigma$ improves the incentives for party 1 to take precaution, and, thus, the social cost decreases (the first term is negative). At the same time, the incentives of party 2 are reduced, and, hence, the social cost rises (the second term is positive). Thus, changes in $\sigma$ generate contrasting effects on the social cost. Evaluating Exp. (4) at $\sigma=0$ and at $\sigma=1$, we have, respectively:

$$
\left\{\begin{array}{l}
S^{\prime}(0)=-\pi f(0) h^{2}<0 \\
S^{\prime}(1)=(1-\pi) f(0) h^{2}>0
\end{array}\right.
$$

From Exp. (5) it is evident that the social cost decreases if $\sigma$ deviates from 0 or 1 towards internal values. Thus, sharing rules must yield a lower social cost than all-or-nothing rules.

To illustrate the logic of this result, if we move from $\sigma=0$ to some internal value of $\sigma$, party 1 will take more precaution, while party 2 will reduce his. Thus, party 1 will prevent some accidents that he would not have prevented at $\sigma=0$, and, to the contrary, party 2 will let some accidents occur that he would have prevented at $\sigma=0$. The accidents that party 1 now prevents are more harmful than those that party 2 lets occur, as their cost of precaution is very small (say \$1) if compared to the harm (\$100), and namely below $\sigma h$ (we are considering a $\sigma$ close to zero). Correspondingly, the cost of avoiding the accidents that party 2 lets occur is relatively very high (say \$99) and namely above $(1-\sigma) h$. Therefore, there is a social gain in trading off the former (more harmful) for the latter (less harmful) accidents. The same symmetrically applies to a reduction of $\sigma$ from $\sigma=1$ towards internal values.

This result proves that there is always the possibility to improve social welfare by switching from an all-or-nothing rule to some sharing of the accident loss. In principle, this is a rewarding choice because the accidents we let occur by switching rules has a lower net social cost than those 
we prevent, even if the probabilities for the two types of accidents are different; by finely tuning the share, it is always possible to capture this benefit.

The value of the optimal sharing is easy to determine for symmetric distributions - that is, in situations in which the cost of precaution is distributed symmetrically around its mean. In this case, the social cost is minimized by a sharing equal to the probability of being the avoider. For example, if the probabilities of being the avoider are $2 / 3$ for the injurer and $1 / 3$ for the victim, the optimal sharing requires that the injurer pays $2 / 3$ of the harm and the victim bears the remaining $1 / 3$.

Two compelling examples of symmetric distributions are the uniform distribution, which we will study in the next section, and the bell-shaped normal distribution. These cases are likely to play an important role in reality. The uniform distribution, as we will argue, may be used to describe situations is which there is a lack of information concerning the actual shape of the distribution function. The normal distribution describes cases in which the cost of precaution is randomly distributed.

Proposition 2. In unilateral-care cases, if the distribution of avoider types is symmetric, the optimal sharing rule is the one that shares the harm between the parties according to the probability of each party being the avoider, $\sigma=\pi$.

Proof. Since the distribution is symmetric, we have $f(\sigma h)=f([1-\sigma] h)$. Substituting the latter equivalence into Exp. (4) and rearranging, we can calculate the following first order condition for an optimal sharing $\sigma^{*}$ :

$$
S^{\prime}(\sigma)=f(\sigma h) h^{2}(\sigma-\pi)=0
$$

which is clearly satisfied at $\sigma^{*}=\pi$. The second order condition yields:

$$
S^{\prime \prime}(\sigma)=f^{\prime}(\sigma h) h^{3}(\sigma-\pi)+f(\sigma h) h^{2}>0
$$

The first addendum is zero at the optimum and the other terms are all positive. Therefore, Exp. (7) is satisfied at the stationary point, and, hence, $\sigma^{*}$ is a local minimum. Since $\sigma^{*}$ is the unique solution to (6) and the functions we employ are differentiable, we can infer that $\sigma^{*}$ is also a global minimum.

\subsection{The uniform-distribution case}

When the avoider's costs of precautions are uniformly distributed, each type $c$ occurs with the same probability. The uniform distribution is a special case of the more general set of symmetric distributions that we have studied in the previous section. Therefore, the optimal sharing of a party 
is also equal to that party's probability of being the avoider in this case. When the avoider types are distributed uniformly, we have $f(c)=1 / h$ and $F(c)=c / h$. By making some simple substitutions into Exp. (1), we can write the social cost as follows:

$$
S(\sigma)=\pi \frac{(1-\sigma)^{2} h}{2}+(1-\pi) \frac{\sigma^{2} h}{2} \quad \text { or } \quad S(\sigma)=\frac{h}{2}\left(\sigma^{2}-2 \pi \sigma+\pi\right)
$$

In this case, the precaution cost function depicted in figure 1 takes the form of a linear function with slope equal to $h$; thus, the social cost may also be graphically seen as the weighed sum of the areas of two triangles of basis $\sigma$ and $(1-\sigma)$ and height $\sigma h$ and $(1-\sigma) h$, respectively - as it is clear from the first Exp. in (8).

It is redundant to verify that, as a result of proposition 2, if the distribution of the avoider types is uniform, the socially optimal rule is the one that shares the harm between the parties according to the probability of each party being the avoider, $\sigma^{*}=\pi$. It can be easily shown that this value of $\sigma$ uniquely minimizes Exp. (8), which is strictly convex. Now, let us derive some additional corollaries.

Corollary 2.a. In unilateral-care cases, if the distribution of the avoider types is uniform, the difference between the social loss due the optimal sharing and the social loss due the optimal all-or-nothing rule increases when $\pi$ approaches $1 / 2$; at $\pi=1 / 2$ the social loss due to the optimal sharing rule is half the social loss due to the optimal all-or-nothing rule.

Proof. The optimal all-or-nothing rule makes the party with the highest probability bear the harm; ${ }^{22}$ hence, the probability that an accident occurs is given by $\min \{\pi, 1-\pi\}$. Let us assume that $\pi \leq 1-\pi$, i.e. let us assume $\pi \leq 1 / 2$ (if the opposite case obtains, we simply re-label the probabilities). The social loss under the optimal all-or-nothing rule is hence equal to $S(0)=\pi h / 2$. By substituting $\sigma=\pi$ into Exp. (8) and rearranging we obtain that the social loss due to the optimal sharing rule is equal to $S(\pi)=\pi h / 2-\pi^{2} h / 2$. The difference between the $S(0)$ and $S(\pi)$ is $\pi^{2} h / 2$, which increases in $\pi$ at an increasing rate (equal to $\pi h$ ) and is maximal when $\pi=1 / 2$. At this level of $\pi, S(0)=h / 4$, while $S(\pi)$ $=h / 8$.

Corollary 2.b. In unilateral-care cases, any sharing rule $0<\sigma<1$ yields a lower social cost than any all-or-nothing rule if the distribution of the avoider types is uniform and if parties have equal probabilities of being the avoider $(\pi=1 / 2)$.

\footnotetext{
${ }^{22}$ It is evident that the social cost is lower if the party that takes precaution is the one with the higher probability of being the avoider, given that the type distribution is the same for both parties. Consider Exp. (1) when $\sigma=1$ or $\sigma=0$.
} 
Proof. Since the social cost is a convex function of $\sigma$, it is at its maximum when $\sigma$ equals either 1 or 0 . By substituting $\pi=1 / 2$ into Exp. (8) we can calculate the social loss for the two all-or-nothing rules, $S(0)=S(1)=h / 4$. Since $\sigma=0$ and $\sigma=1$ yield the same (maximum) social cost, any other sharing is preferable. It is evident that the same does not hold if $\pi$ is not equal to $1 / 2$.

Corollary 2.c. In unilateral-care cases, if the distribution of the avoider types is uniform, the optimal sharing rule $\sigma^{*}=\pi$ yields (if $\pi=1 / 2$ ) the same number of accidents as or (if $\pi \neq 1 / 2$ ) a higher number than the optimal all-or-nothing rule.

Proof. By substituting $F(\sigma h)=\sigma h / h=\sigma$ and $\sigma=\pi$ into Exp. (2), we obtain that the probability of an accident under the optimal sharing rule is $P(\pi)=2 \pi(1-\pi)$. Assuming as above that $\pi \leq 1 / 2$ (and re-labeling, otherwise), under the optimal all-or-nothing rule the probability that an accident occurs is $\pi$. It is easy to show that $P(\pi)=2 \pi(1-\pi)=1 / 2$ if $\pi=1 / 2$ and that $P(\pi)=2 \pi(1-\pi)>1 / 2$ if $\pi<1 / 2$.

\section{[figure 2] - [figure 3]}

Our results suggest that, for uniform distributions, the sanction should be apportioned among potential violators according to the probability of guilt. The social-loss saving due to the filtering effect may be very relevant, and it depends on the probability of the parties being the avoider. When parties are equally likely to be the avoider (the probability is $1 / 2$ for each of them), the filtering effect saves half of the social loss that would occur under an all-or-nothing rule. The magnitude of this advantage tends to decrease (although it remains positive) when the parties' probabilities diverge from each other, as sharing tends to cause increasingly more accidents compared to all-ornothing rules.

Another important characteristic of the case in which the probability of being the avoider is $1 / 2$ for each party is that any sharing is preferable to an all-or-nothing rule although the optimal sharing in this case is $1 / 2$ as we have remarked. This means that even if the sharing rule cannot be applied with perfect accuracy, errors in the setting or the calculation of the shares do not undermine the superiority of such a rule over all-or-nothing rules.

Concerning the number of accidents or, more in general, of violations, sharing rules tend to perform as well as all-or-nothing rules only if the probability of being the avoider is $1 / 2$ for each party. In all other cases, sharing yields more violations. It does not seem obvious that an increase in the number of accidents may improve social welfare, but it is worth remarking that even though 
more accidents occur, they are the less harmful ones since the most harmful ones are filtered out. This point may be exploited to emphasize a potential conflict between the goal of maximizing the probability of apprehending the guilty - which suggests that the party with the higher probability should be sanctioned - and the goal of maximizing social welfare - which requires that the sanction should be shared. ${ }^{23}$

\section{The model of alternative care}

In the previous section, we analyzed a model in which only one party can avoid the accident at a reasonable cost (a cost less than the harm). However, in reality, it is often the case that both parties can take precaution at a reasonable (though not the same) cost and that one party's precaution is sufficient to prevent the accident. In the literature, this situation is referred to as alternative care.

Let us consider the case in which both parties can take precaution, which can have a cost that varies from 0 to $g$. The value of $g$ amounts to a limit to the range of the parties' types, and it can be equal to or higher than the harm. The point we will make in this section is that if the parties' costs of precautions range sufficiently beyond the harm, then the filtering effect also improves social welfare in alternative-care cases. The reason is that sharing in alternative-care cases filters out both the most harmful accidents and the highest precaution costs (thus, accidents are prevented at a lower average cost), but it may create conditions under which no party takes precaution. It is also vulnerable to reciprocal free riding by the parties, who attempt to externalize precaution costs on each other. We will show that the advantages of sharing augment and its shortcomings weaken when the range $g$ of the parties' costs of precaution expands beyond the harm - that is, when some avoiders have a cost of precaution significantly higher than the harm.

In addition to our previous notation, let: ${ }^{24}$

$g_{i}=$ upper limit for the range of the parties' types, with $g_{i} \geq h$ and $i=1,2$;

$c=$ each party's type, $0 \leq c \leq g ; c$ is distributed according to a density function $f_{i}(c)$ and a cumulative distribution $F_{i}(c)$, with $F_{i}(0)=0, F_{i}\left(g_{i}\right)=0$ (note that $F_{i}(h)=0$ only if $h=g_{i}$ ), and $i=1,2$.

It is convenient to calculate the net social cost as the sum of the costs of precautions taken by the

\footnotetext{
${ }^{23}$ A related point concerns transaction costs. An increase in the number of accidents may increase the cost of applying a sharing rule over the cost of implementing an all-or-nothing rule. Comparative negligence in tort has long been said to be more expensive to administer than its all-or-nothing alternative, such as simple or contributory negligence. Our analysis suggests that comparative negligence may yield higher administrative costs due to more cases to adjudicate rather than (or in addition to) a higher cost per case.

${ }^{24}$ Clearly, there is no need to define the probability of being the avoider since both parties are in fact avoiders. Implicitly, the parties' probabilities of being the avoider depend upon the distributions of their types.
} 
parties and the accident costs minus the minimum between the parties' cost and the harm (the ideal situation); ${ }^{25}$ since the latter does not depend on the share $\sigma$, it can be treated as a constant $K .{ }^{26}$

$$
S\left(c_{1}, c_{2}\right)=\int_{0}^{c_{1}} c f_{1}(c) d c+\int_{0}^{c_{2}} c f_{2}(c) d c+\left[1-F_{1}\left(c_{1}\right)\right]\left[1-F_{2}\left(c_{2}\right)\right] h-K
$$

The values $c_{1}$ and $c_{2}$ are the maximum costs that parties take given the legal rule. The probability that an accident occurs in alternative-care cases is given by the following expression.

$$
P\left(c_{1}, c_{2}\right)=\left[1-F_{1}\left(c_{1}\right)\right]\left[1-F_{2}\left(c_{2}\right)\right]
$$

Parties' precaution decisions in alternative care not only depend upon their share in the harm but also upon their expectations concerning each other's behavior. To illustrate, if the share of party 1 is $\sigma h$, party 1 will actually bear this cost only if the other party does not take precaution and the accident occurs. If parties act simultaneously, as we assume, then their maximal precaution costs may be calculated as follows:

$$
\left\{\begin{array}{l}
c_{1}=\left[1-F_{2}\left(c_{2}\right)\right] \sigma h \\
c_{2}=\left[1-F_{1}\left(c_{1}\right)\right](1-\sigma) h
\end{array}\right.
$$

Exp. (11) shows the maximal costs that parties are willing to bear to prevent the accident. This maximal cost is equal to the expected cost of not taking precaution, which, in turn, is equal to the probability that the other party will not take precaution (otherwise there is no harm), times the party's share, times the harm. Thus, parties only take precaution if their cost of precaution is less than this value. As in the unilateral-care case, the filtering effect does, under a sufficient condition, enhance social welfare. Details concerning the following proofs are given in the appendix.

Proposition 3. In alternative-care cases, if $g_{i}>h$, there exists some sharing that yields a lower social loss than all-or-nothing rules.

Proof. Calculating the total derivative of Exp. (9) with respect to $\sigma$ and evaluating it at $\sigma=0$ and at $\sigma=1$, we have, respectively:

\footnotetext{
${ }^{25}$ In the ideal case if at least one party's cost is below the harm, precaution is only taken by the least-cost avoider, and no harm occurs. Otherwise, precaution is not taken and the harm materializes.

${ }^{26}$ The first integral in Exp. (9) may be interpreted as the average cost of precaution for party 1 times the probability that party 1 takes precaution. The average cost of precaution is to be calculated as the integral divided by $F\left(c_{1}\right)$, because precaution only ranges from 0 to $c_{l}$. The probability that party 1 takes precaution is also equal to $F\left(c_{l}\right)$. Therefore, we can simplify and only consider the integral. The same applies to party 2 . The third term is the expected cost of the accidents that actually occur when no party takes precaution.
} 


$$
\left\{\begin{array}{l}
S^{\prime}(0)=-f_{1}(0)\left[1-F_{2}(h)\right]^{2} h^{2}<0 \\
S^{\prime}(1)=f_{2}(0)\left[1-F_{1}(h)\right]^{2} h^{2}>0
\end{array}\right.
$$

Since the social cost decreases when $\sigma$ departs from 0 or 1 toward internal values, there exists some sharing which yields a lower social cost than the all-or-nothing rules. It is to be noticed that if $g_{i}=h$, then $F_{i}(h)=1$, and, hence, both expressions equal zero. In this case, the social cost does not change by switching rules.

The intuition behind this result is as follows. When $g_{l}$ and $g_{2}$ range beyond $h$, there will be cases in which at least one party's cost of precaution is higher than the harm. On the one hand, the incentives to free ride diminish as a party may rely less often on the other party's precaution. On the other hand, those cases are in fact of unilateral-care type, in relation to which the superiority of sharing has already been proven.

The optimal sharing will depend on the specific characteristics of the parties' types distributions. Nevertheless, it is possible to show that, under certain conditions, equal sharing may be preferable to all-or-nothing rules, although this is not necessarily the optimal sharing.

Proposition 4. In alternative-care cases, if the parties' types are distributed according to the same distribution function, there exists some level of $g$ above which equal sharing yields a lower social cost than all-or-nothing rules.

Proof. If $f_{l}(c)=f_{2}(c)=f(c)$, and if $g_{1}=g_{2}=g$, then we can evaluate Exp. (9) at $\sigma=0, \sigma=1$, and $\sigma=$ $1 / 2$, respectively, as follows:

$$
\left\{\begin{array}{l}
S(0)=S(1)=\int_{0}^{h} c f(c) d c+[1-F(h)] h \\
S\left(\frac{1}{2}\right)=2 \int_{0}^{c} c f(c) d c+\left[1-F\left(c^{\wedge}\right)\right]^{2} h
\end{array}\right.
$$

with $c^{\wedge}=\left[1-F\left(\mathrm{c}^{\wedge}\right)\right] h / 2<h / 2$. The relative performance of the different rules may be expressed as follows:

$$
S(0)-S\left(\frac{1}{2}\right)=\int_{0}^{h} c f(c) d c-2 \int_{0}^{c} c f(c) d c+\left\{[1-F(h)]-\left[1-F\left(c^{\wedge}\right)\right]^{2}\right\} h
$$

It is easy to show that the first term is surely larger than the second because $c^{\wedge}<h / 2$. The third term is negative when $g=h$ (because $F(g)=0$ ) but approaches 0 as $h$ decreases below $g$ (because both 1$F(h)$ and $1-F\left(c^{\wedge}\right)$ move toward 1). Therefore, there exists some $g$ sufficiently larger than $h$ such that Exp. (14) is positive, and, hence, the social cost is lower with $\sigma=1 / 2$ than under all-or-nothing 
rules.

This result may be interpreted in the light of our previous results concerning symmetric distributions in the unilateral-care case. In a way, the symmetry here is given by the fact that the parties' distributions are the same, and, as for symmetrical distributions, we are advocating a sharing equal to the probability of being the avoider. In fact, having equal distributions also means having equal parties' probabilities of being the avoider. Equal sharing, however, only becomes viable when the range of the cost of precaution becomes sufficiently large, for the same reasons given above.

\subsection{The uniform-distribution case}

In this section, we study in more detail the simpler case in which parties' types are distributed according to the same uniform distribution function. Therefore, we have $f_{l}(c)=f_{2}(c)=f(c)=1 / h$, $F_{l}(c)=F_{2}(c)=F(c)=c / h$, and $g_{l}=g_{2}=g$. Substituting into Exp. (9) and Exp. (11), and rearranging, we can write the social cost as a function of the sharing, as follows:

$$
S(\sigma)=\frac{g^{3} h(2 g-h)}{2\left[g^{2}-\sigma(1-\sigma) h^{2}\right]^{2}}-\frac{g h^{2} \sigma(1-\sigma)}{g^{2}-\sigma(1-\sigma) h^{2}}-K
$$

As enunciated in Proposition 3, if $g>h$, the social cost is minimized by some internal values of $\sigma$. Proposition 4, instead, implies that equal sharing, even though it may not be the optimal sharing, still yields a lower social cost than all-or-nothing rules if $g$ is sufficiently larger than $h$. Moreover, since the probability that an accident occurs is given by the product between the probabilities that each party does not take precaution, these probabilities will be equal when the loss is equally shared, and, hence, their product will be at the maximal level. If, on the contrary, the loss is concentrated on one party, at least that party will take precaution whenever his cost is less than the harm, and, thus, there will be fewer accidents. The following corollaries (proved in the appendix) refine these claims.

Corollary 3.a In alternative-care cases, if the parties' types are distributed according to the same uniform distribution function, for $h<g<3 h / 2$, the socially optimal shares are some values $\sigma_{a}$ $<1 / 2$ and $\sigma_{b}>1 / 2$ (or, indifferently, $\sigma_{a}>1 / 2$ and $\sigma_{b}<1 / 2$ ), subject to $\sigma_{a}+\sigma_{b}=1 ; \sigma=1 / 2$ is instead a local maximum. As $g$ moves toward 3h/2, the optimal shares move toward 1/2.

Corollary 3.b In alternative-care cases, if the parties' types are distributed according to the same uniform distribution function, for $g>3 h / 2$, then $\sigma=1 / 2$ is the optimal sharing rule. 
Corollary 4.a In alternative-care cases, if the parties' types are distributed according to the same uniform distribution function, for $g>h\left(1+3^{1 / 2}\right) / 2$, then $\sigma=1 / 2$ yields a lower social loss than all-or-nothing rules.

The corollaries show that sharing rules are superior to all-or-nothing rules for any $g>h$. As $g$ becomes even larger than $h$, the optimal sharing rule changes. Initially, it is optimal to share the loss unequally among the parties. As the difference between $g$ and $h$ increases, equal sharing, although it is not yet the optimal sharing, is still preferable to all-or-nothing rules; figure 4 depicts this case in which the social cost function is w-shaped. When $g$ is above a certain threshold, equal sharing is the optimal sharing. In this case, the social cost function assumes a u-shaped convex form.

\section{[figure 4]}

Corollary 4.b In alternative-care cases, if the parties' types are distributed according to the same uniform distribution function, then equal sharing yields the highest probability of accidents.

Proof. For uniform distributions, Exp. (10) may be rewritten as follows:

$$
P\left(c_{1}, c_{2}\right)=\left[1-\frac{c_{1}}{g}\right]\left[1-\frac{c_{2}}{g}\right]
$$

This expression is maximized when $c_{1}=c_{2}$, and it is at its minimal level when one of them is equal to $h$.

As we have already remarked for the unilateral-care case, there might be a potential conflict between reducing the probability of accidents and minimizing their social cost. Equal sharing tends to yield many more accidents than all-or-nothing rules even in those cases in which it minimizes the social cost.

\section{Conclusions and applications}

What should courts decide when they do not know which of the parties should have done more to prevent an accident or the failure of a contractual relationship? We have argued that sharing rules have an important advantage over all-or-nothing rules: they filter out the losses that were relatively less expensive to prevent. Since the most notorious sharing rule is comparative negligence, the prose of our model refers to an accident context. Yet, the filtering effect of sharing is a more general principle, which applies to a vast array of seemingly different areas of the law ranging from tort and contract to law enforcement. 
In a broad sense, this article discusses the general enforcement problem of how to allocate incentives when the group of potential violators and their probabilities of guilt are known, but it is not possible to identify the actual violator ex post. In an accident context, the problem is to identify the avoider between the injurer and the victim when their costs of precaution are unverifiable. In divorce cases, this means singling out which of the partners could have saved the relationship. In employment cases, the problem may be one of finding who is responsible for the lack of cooperation between the employer and his employee. In communal liability cases, there may be an unidentifiable member of a tribe who has caused harm to a neighboring tribe. In law enforcement, the issue may be related to the allocation of investigation effort between two criminal groups.

If our analysis applies to a case, the next question is what guidelines it could provide for the courts. It is instructive to make a distinction between different typologies of accidents (or, in general, violations). Pure unilateral-care cases are those cases in which the harm could have been avoided by one party only. We have discussed this case at length and shown that sharing always dominates all-or-nothing rules. Pure alternative-care cases are those cases in which either party could have avoided the harm at reasonable (even though different) costs. We have shown that the case for sharing is seriously weakened. Mixed alternative-care cases are those in which parties' costs of precaution range beyond the harm and thus consist of a portion of pure alternative-care cases and one of unilateral-care cases. We have argued that if the range is sufficiently large, sharing regains its advantage. We have not discussed the obvious case for sharing under joint care. In our framework, it turns out that if both parties were to take precaution, all-or-nothing rules prevent no accident at all, while sharing still yields some positive level of deterrence.

Therefore, we suspect that - even beyond the cases in which our main claims have been proven - sharing may, in reality, be more likely than not to dominate all-or-nothing rules when courts have no information about the accident typology unless the accident is clearly a pure alternative-care type. Our analysis also suggests that, in general, a 50/50 sharing may be recommendable.

It is also worthwhile remarking that if all-or-nothing rules are applied in a way that cannot be predicted ex ante, then their effects are equivalent to a stochastic sharing rule. In this case, the only difference between sharing and all-or-nothing rules would be the risk involved in the probabilistic attribution of responsibility, which is absent when sharing rules are announced ex ante and correctly implemented.

\subsection{Tort}

As we suggested in the introduction, our analysis may furnish a justification for comparative negligence. Strictly speaking, comparative negligence shares the loss when both the injurer and the 
victim are found negligent, which cannot be the case in our unilateral-care model. What we are advocating is, in fact, the sharing of the loss when fault cannot be proven.

Loss sharing in tort has also been advocated under other headings. Comparative causation, for example, refers to the sharing of the loss between non-negligent parties and mirrors the comparative negligence rule. In this case, sharing aims at controlling the incentives to take optimal activity level rather than care. When an accident has occurred, notwithstanding the fact that parties took optimal care, our analysis suggests that sharing the loss could improve parties' incentives with respect to the level of activity. ${ }^{27}$

Also, rules of communal liability may amount to a sharing of the loss among several potential tortfeasors. ${ }^{28}$ In ancient societies, it was common that if a member of a tribe did harm to another tribe, compensation was to be sought from the tortfeasor's group. In these cases, the literature has focused on the reasons for implementing different forms of liability rather than on their sharing effects. ${ }^{29}$ Current explanations in the literature focus on the need to give each individual incentives to monitor the others. ${ }^{30} \mathrm{We}$ suggest that sharing may be supported by its filtering properties in this case as well. That communal liability disappeared in more modern societies is also in line with our framework. Over time, it might have become cheaper (and, more often, technically possible) to find out what individual was responsible. As the non-verifiability problem disappears, the filtering justification for sharing rules also disappears.

Empirical studies have concluded that comparative negligence gives parties weaker incentives to take precaution than contributory negligence. ${ }^{31}$ These results should be interpreted with caution. Our analysis shows that sharing rules are indeed likely to (even though they do not always) increase the number of accidents. This means that parties will more often be careless. The social gains of comparative negligence consist of the fact that injurers, on average, spend less in precaution. This means that injurers who exercise care have, on average, less care costs. In other words, under comparative negligence, there are more accidents, and less is spent on precaution, but what is spent

\footnotetext{
${ }^{27}$ See Parisi and Fon (forthcoming) for an analysis of loss sharing between non-negligent parties as a function of their causal contribution to the accident. They do not touch upon the points we make. Also, Shavell (1985) makes a point in favor of sharing, when causation is uncertain for both the courts and the parties. The distinction between care and activity level, although already present in earlier studies, was first formalized by Shavell (1980).

28 Kornhauser and Revesz (1990 and 1993) provide an analysis of loss-sharing among several actual injurers but make points that are different from ours.

${ }^{29}$ Sykes (1981) and Kornhauser (1982) provided the first breakthroughs in the economic understanding of rules of vicarious and communal liability and the standard view on their desirability.

${ }^{30}$ See Posner (1980) and Parisi and Dari-Mattiacci (2004).

${ }^{31}$ White (1989) (comparative negligence gives parties weaker incentives to take precaution than contributory negligence); Sloan, Reilly, and Schenzler (1995) used self-reported data on patterns of alcohol use among individuals and found that switching from contributory to comparative negligence increased binge drinking. Flanigan, Johnson, Winkler, and Ferguson (1989) found that comparative negligence is associated with higher automobile liability insurance premiums, but they did not investigate whether this increase was due to more claims towards injurers or to more accidents. On the comparison between contributory and comparative negligence see also Schwartz (1978).
} 
on precaution is relatively well-spent. Therefore, the current empirical literature does not allow us to make any statements on whether comparative negligence worsens the parties' incentives. A change in the number of accidents is an evident effect of tort reforms, while a change in their social cost may be a rather hidden feature, and it is more cumbersome to measure. Therefore, the tension between, on one hand, reducing the number of accidents or the number of careless parties and, on the other, reducing the social cost may be of relevant political impact because policies that pursue the latter goal at the expense of the former may be favoured by uninformed voters.

\subsection{Law enforcement}

Our analysis also bears on issues of law enforcement and particularly on the question whether investigation effort should be shared among the population of potential violators or focused on a subgroup. An example is useful for clarification. Assume that a robbery has been perpetrated and that there are only two criminal groups in the city with different probabilities of hosting the thief. If all investigation effort is directed toward one of the two groups, the probability of finding and proving the guilt of the criminal, if he is there, is equal to 1; if he is in the other group, the probability is obviously zero. If policemen are sent to inquire into both groups, the probability is less than 1 for both and proportional to the number of policemen. Sharing the policemen between the two groups can be analogized to the sharing of the loss in an accident context. The chosen policy produces ex ante incentives for the two groups, which can be studied by applying our model.

A recent article on this topic focuses on the effects of varying enforcement resources and concludes that the optimal distribution of enforcement effort depends on the availability of these resources. ${ }^{32}$ In general, the more resources are available, the more optimal law enforcement effort tends to be uniformly distributed under the assumption that the violators' probabilities of guilt are the same. Instead we make a different point. Our focus is on differences among parties, both with

\footnotetext{
${ }^{32}$ Lando and Shavell (2004) discuss this under the label 'focusing law enforcement effort'. Our study interacts with theirs in several respects and deviates in others. First, focusing is not the opposite of sharing. Focusing denotes any policy that is different from uniformly sharing police effort amongst the population of violators (that is sharing 50/50). In our framework, sharing denotes any policy that is different from focusing the full enforcement effort on a subgroup of the violators (an all-or-nothing rule). There exists, therefore, a grey zone between uniform sharing (50/50) and full focusing $(0 / 100$ or $100 / 0)$ in which law enforcement effort is shared between two subgroups of violators, but not uniformly. Lando and Shavell also call this case focusing, stressing the fact that law effort is not distributed uniformly. We call it sharing, emphasizing the fact that law enforcement effort is not concentrated on one subgroup only. Second, with these considerations in mind, it is easy to see that our findings are compatible with those by Lando and Shavell, as both of us show in fact the benefits of distributing law enforcement effort between two subgroups of potential violators with varying proportions. For both of us, the sanction is given. They vary enforcement levels by means of redistributing enforcement effort and, thus, through variations in the probability of apprehension. We reach the same result by means of sharing a fixed probability times sanction mix between the parties. It is easy to see that, beyond terminology and mathematics, the two approaches converge. In our setting however, the enforcement resources are implicitly given as fixed, as the probability of apprehension is given and the sanction is set equal to the harm.
} 
respect to their probabilities of guilt ${ }^{33}$ and to their varying costs of precautions. ${ }^{34} \mathrm{We}$ study how the optimal sharing varies when the probability of guilt for the parties differs.

\subsection{Marriage contracts}

Our framework applies very well to divorce law, which, in essence, defines the sanctions for breach of marriage contracts. Marriage contracts are notorious examples of contracts where breaching is hard to verify. Courts face enormous difficulties in finding out which of the parties should have done more to save the marriage. They may acquire information on some proxies (like who quit the house first), but, in most cases, they may not succeed in finding out who was (most) responsible for the unsuccessful marriage.

The next question is what 'all-or-nothing rules' and 'sharing rules' mean in this context. Allor-nothing rules make only one party worse off. That party bears all financial losses caused by the termination of the relationship, while the financial status of the other party remains unaffected. A perfectly compensatory expectation measure (that puts one party in the same financial position as during the marriage) can be seen as an all-or-nothing rule. What are sharing rules? Sharing rules make both parties (financially) worse off when they divorce. When both parties have a similar position on the labor market, not awarding alimony to any of the parties results in both parties sharing the loss. If only one of the parties is able to generate an income on the labor market, making that party pay undercompensatory expectation damages or just reliance damages results in loss sharing.

The central question, then, is whether we are dealing with pure alternative-care cases, pure unilateral-care cases, or mixed alternative/unilateral-care cases. 'Pure alternative care' means here that the marriage was worth saving and that each party could have saved the marriage at reasonable (though not equal) costs. This depends, of course, on the benefits of staying together. In societies with weak social security systems, non-subsidized schooling, etc... or societies where people are living at or just above the subsistence level, the costs of divorce are relatively high so that the precaution costs range of the parties may be lower than the harm $(g<h)$. To illustrate, if the precaution range goes from $\$ 0$ to $\$ 200$ while the harm is $\$ 100$, we have a mixed unilateralcare/alternative-care case; but if the harms is $\$ 500$, we are in a pure alternative-care situation (each of the parties can prevent the harm at a reasonable cost).

Our framework provides an alternative explanation for the general tendency in modern legal

\footnotetext{
${ }^{33}$ Lando and Shavell (2004) dismiss this issue as an obvious argument for focusing. However, the issue is not trivial, and we show that complete focusing (all-or-nothing rules) is not in general the optimal response to different probabilities of guilt.

${ }^{34}$ It is immaterial that we determine the parties' type according to their costs of precautions, while Lando and Shavell (2004) refer to the benefit deriving from the violation, as one can be interpreted as the other and vice versa.
} 
systems to replace an all-or-nothing rule (perfectly compensatory expectation measure) by rules that implicitly share the loss (undercompensatory expectation measure, reliance measure and no damages system). The decrease over time of the harm $h$ caused by a divorce transformed pure alternative-care cases into mixed unilateral-care/alternative-care/efficient-breach cases. As a consequence, sharing rules have become superior to the old all-or-nothing regimes.

\subsection{Labor contracts}

Just like in marriage contracts, courts have substantial problems in verifying who was (most) responsible for the failed employment relationship. Unsuccessful employment relationships are not necessarily pure alternative-care situations. It is possible that only one of the parties could have done something (for instance, if the problem was that the employee shirked in non-verifiable ways, it is only that employee who could have solved that problem; if the problem was that the employer created an unpleasant working atmosphere, the employer may have been the only one who was able to solve that problem). Our analysis suggests that sharing is better under these conditions.

Employment contracts are characterized by relatively weak sanctions for contract breach or contract termination. In contrast to general contract law where heavy pressure is put on promises (since the standard remedy for contract breach is the expectation measure), modern legal systems generally put less pressure on staying in an employment relationship. ${ }^{35}$ A clear example is the American termination at will doctrine, which allows any of the parties to stop the co-operation at any time and for any reason without having to pay any form of compensation. This doctrine can be seen as an implicit loss-sharing rule. Both parties bear a part of the transaction costs (the employee has to find a new job, the employer has to find a new worker), both forego the expected profits they hoped to make, and both may lose some relation-specific investments and reliance costs. But contracts that offer more protection to the parties by requiring a notice period (which is the case for most employment contracts in Europe) also have a loss sharing effect. These notice periods give the protected party some extra time to find a replacement contract (and hence reduce the reliance losses), but they do not award any form of compensation to that party (unless the notice period has not been respected).

In addition, our analysis provides a justification for the need of letting the parties make equal relation-specific investments in long-term contracts. ${ }^{36} \mathrm{~A}$ common justification is that this minimizes the hold-up risk (when both have something to lose, a hold-up is less likely then when one party does not have anything to lose). Our analysis suggests an additional justification: if the legal system is unable to sanction contract breach, then equal relation-specific investments implicitly share the

\footnotetext{
${ }^{35}$ De Geest, Siegers, and Vandenberghe (2001).
} 
reliance losses in case of contract breach, and this filters out the breaches (or terminations) that were easiest to prevent.

\subsection{Shares in partnerships}

While our framework focused on loss sharing regimes, it also applies to profit sharing arrangements. The success of a firm depends on the effort levels of many actors, and quite often the effort levels (or costs) of several of these actors are hard to verify. In other words, it may be very hard for judges to find out who should have done a little more in a company. This non-verifiability problem is a central theme in the contemporary literature on industrial organization and personnel economics. While a thorough analysis of the filtering functions of sharing systems in firms is beyond the scope of this article, it seems plausible to presume that our framework also applies to some extent ${ }^{37}$ to profit sharing business arrangements and variable pay contracts.

If the effort levels of more than one actor are non-verifiable, is it then better to give one actor a $100 \%$ hard regime (give her all shares, or give her a fully internalizing variable pay contract) and the others a 100\% soft regime (fixed wages), or is it better to put all actors under an intermediate regime (a share in the profits of a project or a firm, that is higher than 0 and lower than 1)? We have shown that sharing always has a filtering effect. While parties who internalize less than $100 \%$ of the profits they generate have no perfect incentives, profit sharing filters out the most serious incentive problems by preventing losses (or missed opportunities) that could have been prevented with relatively less effort. Whether this filtering benefit outweighs the potential disadvantages of sharing rules (duplicative precaution, or lack of precaution due to free-riding between the parties) depends on the distribution of relative effort costs. We have shown that all-or-nothing rules make sense only for pure alternative-care cases. Often this will not be the case: some commercial losses can be prevented by only one person at reasonable costs, and some commercial opportunities are noticed by only one person. In that case, sharing is better. Our analysis also suggests that parties who have a higher chance of being able to influence the results in a non-verifiable way should receive greater shares, which seems to correspond to the empirical findings.

This suggests that loss sharing rules in tort law and profit sharing arrangements in business markets may have a common underlying economic logic. It should be no surprise to see a switch to comparative negligence in a society in which profit sharing and variable pay arrangements are common practice. The fundamental cause seems to be the 'specification problems' that occur in

\footnotetext{
${ }^{36}$ Becker (1975) lies at the origin of the literature on this point.

${ }^{37}$ One difference between sharing regimes in contracts and torts, is that parties in a contract may have opportunities to solve misunderstandings (resulting in duplicative precaution or no party taking precaution) by communication. This seems to make the case for sharing even stronger in a contractual context.
} 
complex societies: the complexity makes it hard to find out who should do a little more to prevent an accident or to increase profits.

\section{References}

Bar-Gill, Oren and Ben-Shahar, Omri (2003), 'The Uneasy Case for Comparative Negligence', 5 American Law and Economics Review, 433-469.

Becker, Gary S. (1975), Human Capital, $2^{\text {nd }}$ ed., New York, National Bureau of Economic Research.

Brown, John P. (1973), 'Toward an Economic Theory of Liability', 2 Journal of Legal Studies, 323-350.

Buechtemann, Christoph F. and Walwei, Ulrich (1999), 'Employment Security through Dismissal Protection: Market versus Policy Failures', in Backhaus, Jürgen G. (ed.), The Elgar Companion to Law and Economics, Cheltenham. Edward Elgar, 168-182.

Chung, Tai-Yeong (1993), 'Efficiency of Comparative Negligence: A Game Theoretic Analysis', 22 Journal of Legal Studies, 395-404.

Cooter, Robert D. and Ulen, Thomas S. (1986), 'An Economic Case for Comparative Negligence', 61 New York University Law Review, 1067-1110.

Curran, Christopher (1992), 'The Spread of the Comparative Negligence Rule in the United States', 12 International Review of Law and Economics, 317-332.

De Geest, Gerrit, Siegers, Jacques J. and Vandenberghe, Ann-Sophie (2001), 'The Expectation Measure, Labor Contracts, and the Incentive to Work Hard', 21 International Review of Law and Economics, 1-21.

Diamond, Peter A. (1974a), 'Single Activity Accidents', 3 Journal of Legal Studies, 107-162.

Diamond, Peter A. (1974b), 'Accident Law and Resource Allocation', 5 Bell Journal of Economics, 366-406.

Diamond, Peter A. and Mirrlees, James A. (1975), 'On the Assignment of Liability: The Uniform Case, 6 Bell Journal of Economics, 487-516.

Dnes, Anthony W. (2000), 'Marriage Contracts', in Boudewijn Bouckaert and Gerrit De Geest (eds.), Encyclopedia of Law and Economics, vol. III, Cheltenham, Edward Elgar, 864-886.

Edlin, Aaron S. (1994), 'Efficient Standards of Due Care: Should Courts Find More Parties Negligent under Comparative Negligence?', 14 International Review of Law and Economics, 21-34.

Emons, Winand (1990a), 'Efficient Liability Rules for an Economy with Non-identical Individuals', 42 Journal of Public Economics, 89-104.

Emons, Winand (1990b), 'Some Recent Developments in the Economic Analysis of Liability Law: An Introduction', 146 Journal of Institutional and Theoretical Economics, 237-248.

Emons, Winand and Sobel, Joel (1991), 'On the Effectiveness of Liability Rules when Agents Are Not Identical', 58 Review of Economic Studies, 375-390.

Epstein, Richard (1984), 'In Defense of the Contract at Will', 51 University of Chicago Law Review, 947-982. 
Flanigan, George B., Johnson, Joseph E., Winkler, Daniel T., and Ferguson, William (1989), 'Experience from Early Tort Reforms: Comparative Negligence Since 1974', 56 Journal of Risk and Insurance, 525-534

Grady, Mark (1990), 'Multiple Tortfeasors and the Economy of Prevention', 19 Journal of Legal Studies, 653-678.

Green, Jerry (1976), 'On the Optimal Structure of Liability Laws', 7 Bell Journal of Economics, 553-574.

Haddock, David D. and Curran, Christopher (1985), 'An Economic Theory of Comparative Negligence', 14 Journal of Legal Studies, 49-72.

Kornhauser, Lewis A. (1982), 'An Economic Analysis of the Choice between Enterprise and Personal Liability for Accidents', 70 California Law Review, 1345-1392.

Kornhauser, Lewis A. and Revesz, Richard L. (1990), 'Apportioning Damages among Potentially Insolvent Actors', 19 Journal of Legal Studies, 617-651.

Kornhauser, Lewis A. and Revesz, Richard L. (1993), 'Settlements under Joint and Several Liability', 68 New York University Law Review, 427-493

Landes, William M. and Posner, Richard A. (1980), 'Joint and Multiple Tortfeasors: An Economic Analysis', 9 Journal of Legal Studies, 517-555.

Lando, Henrik and Shavell, Steven (2004), "The Advantage of Focusing Law Enforcement Effort", International Review of Law and Economics, forthcoming.

Low, Stuart and Smith, Janet Kiholm (1995), 'Decisions to Retain Attorneys and File Lawsuits: An Examination of the Comparative Negligence Rule in Accident Law', 24 Journal of Legal Studies, 535-557.

Mas-Colell, Andreu, Whinston, Michael D., and Green Jerry R. (1995), Microeconomic Theory, Oxford: Oxford University Press.

Orr, Daniel (1991), 'The Superiority of Comparative Negligence: Another Vote', 20 Journal of Legal Studies, 119-129.

Parisi, Francesco and Dari-Mattiacci, Giuseppe (2004), 'The Rise and Fall of Communal Liability in Ancient Law', 24 International Review of Law and Economics, forthcoming.

Parisi, Francesco and Fon, Vincy (forthcoming), 'Comparative Causation', American Law and Economics Review.

Posner, Richard A. (1980), 'A Theory of Primitive Society, with Special Reference to Law', 23 Journal of Law and Economics, 1-53.

Rea, Samuel A., Jr. (1987), 'The Economics of Comparative Negligence', 7 International Review of Law and Economics, 149-162.

Rubinfeld, Daniel L. (1987), 'The Efficiency of Comparative Negligence', 16 Journal of Legal Studies, 375-394.

Savage, Leonard J. (1954), The Foundations of Statistics, New York: Wiley.

Schäfer, Hans-Bernd and Schönenberger, Andreas (2000), 'Strict Liability versus Negligence', in Bouckaert, Boudewijn and De Geest, Gerrit (eds.), Encyclopedia of Law and Economics, II, Cheltenham, Edward Elgar, 597-624.

Schwartz, Gary T. (1978), "Contributory and Comparative Negligence: A Reappraisal”, 87 Yale Law Journal, 697-727. 
Shavell, Steven (1980), 'Strict Liability versus Negligence', 9 Journal of Legal Studies, 1-25.

Shavell, Steven (1985), 'Uncertainty over Causation and the Determination of Civil Liability', 28 Journal of Law and Economics, 587-609.

Shavell, Steven (1987), Economic Analysis of Accident Law, Cambridge (MA), Harvard University Press.

Sloan, Frank A., Reilly, Bridget A. and Schenzler, Christoph (1995), "Effects of Tort Liability and Insurance on Heavy Drinking and Drinking and Driving", 38 Journal of Law and Economics, 49-77.

Sykes, Alan O. (1981), 'An Efficiency Analysis of Vicarious Liability Under the Law of Agency', 91 Yale Law Journal, 168-206.

White, Michelle J. (1989), 'An Empirical Test of the Comparative and Contributory Negligence Rules in Accident Law', 20 Rand Journal of Economics, 308-330. 


\section{APPENDIX}

Proof of proposition 3. Calculating the total differentials if Exp. (9) with respect to the parties' precautions, we have $d S=\left(\partial S / \partial c_{1}\right) d c_{1}+\left(\partial S / \partial c_{2}\right) d c_{2}$. The values of $d c_{1}$ and $d c_{2}$ can be easily calculated from Exp. (11) as follows:

$$
\left\{\begin{array}{l}
d c_{1}=\frac{\left[1-F_{2}\left(c_{2}\right)\right] h+f_{2}\left(c_{2}\right)\left[1-F_{1}\left(c_{1}\right)\right] \sigma h^{2}}{1-f_{1}\left(c_{1}\right) f_{2}\left(c_{2}\right) \sigma(1-\sigma) h^{2}} d \sigma \\
d c_{2}=-\frac{\left[1-F_{1}\left(c_{1}\right)\right] h+f_{1}\left(c_{1}\right)\left[1-F_{2}\left(c_{2}\right)\right](1-\sigma) h^{2}}{1-f_{1}\left(c_{1}\right) f_{2}\left(c_{2}\right) \sigma(1-\sigma) h^{2}} d \sigma
\end{array}\right.
$$

Substituting and rearranging, we have:

$$
\begin{gathered}
\frac{d S}{d \sigma}=\frac{h}{1-f_{1}\left(c_{1}\right) f_{2}\left(c_{2}\right) \sigma(1-\sigma) h^{2}}\left\{f_{1}\left(c_{1}\right)\left[1-F_{2}\left(c_{2}\right)\right]\left(c_{1}-\left[1-F_{2}\left(c_{2}\right)\right] h\right)+\right. \\
-f_{2}\left(c_{2}\right)\left[1-F_{1}\left(c_{1}\right)\right]\left(c_{2}-\left[1-F_{1}\left(c_{1}\right)\right] h\right) \\
\left.+f_{1}\left(c_{1}\right) f_{2}\left(c_{2}\right)\left(c_{1}\left[1-F_{1}\left(c_{1}\right)\right] \sigma h-c_{2}\left[1-F_{2}\left(c_{2}\right)\right](1-\sigma) h+\left[1-F_{1}\left(c_{1}\right)\right]\left[1-F_{2}\left(c_{2}\right)\right](1-2 \sigma) h^{2}\right)\right\}
\end{gathered}
$$

The expression in brackets can be interpreted as follows: the term in the first line measures the direct effect on $S$ of changes in $\sigma$ through $c_{1}$, the term in the second line measures the direct effect on $S$ of changes in $\sigma$ through $c_{2}$, the term in the third line measures the change in $S$ due to the interplay of $c_{1}$ and $c_{2}$ (the same can be said about the denominator).

As it can be easily verified in Exp. (11), if $\sigma=0$, then we have $c_{1}=0, F_{I}\left(c_{1}\right)=0, c_{2}=h, F_{2}\left(c_{2}\right)$ $\leq 1$ (the latter sign is an equality if $h=g$ ). Likewise, if $\sigma=1$, then we have $c_{1}=h, F_{l}\left(c_{1}\right) \leq 1, c_{2}=$ $0, F_{2}\left(c_{2}\right)=0$. Substituting these values into Exp. (18) and rearranging we have Exp. (12).

Proof of proposition 4. Exp. (13) is calculated by making the same substitutions as at the end of the former proof.

Proof of corollaries 3.a and 3.b. After substituting $f_{l}(c)=f_{2}(c)=f(c)=1 / h, F_{l}(c)=F_{2}(c)=F(c)=$ $c / h$, and $g_{1}=g_{2}=g$ into Exp. (11), the parties' precautions decisions can be written as follows:

$$
\left\{\begin{array}{l}
c_{1}=\frac{\sigma g h[g-(1-\sigma) h]}{g^{2}-\sigma(1-\sigma) h^{2}} \\
c_{2}=\frac{(1-\sigma) g h[g-\sigma h]}{g^{2}-\sigma(1-\sigma) h^{2}}
\end{array}\right.
$$


Substituting these values into Exp. (9) and rearranging, we obtain Exp. (15). Differentiating with respect to $\sigma$, we have the following first order condition:

$$
S^{\prime}(\sigma)=\frac{2 g^{3} h^{2}}{\left[g^{2}-\sigma(1-\sigma) h^{2}\right]^{3}}\left(\frac{1}{2}-\sigma\right)\left[\sigma(1-\sigma) h^{2}-(g-h)^{2}\right]=0
$$

It is easy to see that if $g>h$, the first term is always positive for any value of $\sigma$. If $h<g<3 h / 2$, Exp. (20) has three solutions. One solution is $\sigma_{1 / 2}=1 / 2$, at which level of $\sigma$ the second term is zero. The other two solutions are those levels of $\sigma$ such that the third term is equal to zero. They can be written as follows:

$$
\left\{\begin{array}{l}
\sigma_{a}=\frac{1}{2}\left(1-\frac{\sqrt{8 g h-3 h^{2}-4 g^{2}}}{h}\right) \\
\sigma_{b}=\frac{1}{2}\left(1+\frac{\sqrt{8 g h-3 h^{2}-4 g^{2}}}{h}\right)
\end{array}\right.
$$

If $g>3 h / 2$, the only solution is $\sigma_{1 / 2}$, as the third term in Exp. (20) has no real root. Differentiating again, we have:

$$
S^{\prime \prime}(\sigma)=g^{3} h^{2} \frac{2 g^{2}-4 g h+3 h^{2}-6 \sigma(1-\sigma) h^{2}}{\left[g^{2}-\sigma(1-\sigma) h^{2}\right]^{3}}+(2 \sigma-1)^{2} 3 g^{3} h^{4} \frac{\sigma(1-\sigma) h^{2}-(g-h)^{2}}{\left[g^{2}-\sigma(1-\sigma) h^{2}\right]^{4}}
$$

It is convenient to note that the second term is zero at all stationary values (at $\sigma_{1 / 2}$ we have $2 \sigma-1=$ 0 , while at $\sigma_{a}$ and $\sigma_{b}$ the numerator is zero). Calculating the sign of the first term when $h<g<3 h / 2$, we obtain that the expression is negative at $\sigma_{1 / 2}$ (thus, this is a local maximum) and positive at $\sigma_{a}$ and $\sigma_{b}$ (thus, these are local minima). Looking at figure 4 , we see in fact that the social cost function is w-shaped. It is also easy to see from Exp. (21) that $\sigma_{a}$ and $\sigma_{b}$ are situated to the left and to the right, respectively, of $\sigma_{1 / 2}$ and that their sum is equal to 1 . Furthermore, they approach 0 and 1 , respectively, when $g$ decreases toward $h$, and they converge toward $\sigma_{1 / 2}$ when $g$ approaches $3 h / 2$.

When $g>3 / h 2$, the first term of Exp. (22) is positive for any value of $\sigma$. Thus, the social cost function is an ordinary convex $u$-shaped function, and $\sigma_{1 / 2}$ is the unique minimum.

Proof of corollary 4.a. Evaluating Exp. (14) for the uniform distribution, we have:

$$
S(0)-S\left(\frac{1}{2}\right)=\frac{h}{2 g}(2 g-h)-g h \frac{4 g+h}{(2 g+h)^{2}}
$$

This expression is positive for $g>\left(1+3^{1 / 2}\right) h / 2$. Therefore, when $g$ is above this threshold, the social 
cost is lower at $\sigma_{1 / 2}$ than under all-or-nothing rules. It is worth noticing that $\left(1+3^{1 / 2}\right) h / 2<3 h / 2$; that is, $\sigma_{1 / 2}$ may be preferable to all-or-nothing rules even if this is not the optimal sharing. In this case, looking at figure $4, \sigma_{1 / 2}$ is a local maximum but yields a social cost that is less than the social cost at the corner values.

Proof of corollary 4.b. Substituting the values of Exp. (19) into Exp. (16), we have:

$$
P(\sigma)=\frac{g^{2}(g-\sigma h)[g-(1-\sigma) h]}{\left[g^{2}-\sigma(1-\sigma) h^{2}\right]^{2}}
$$

The first order condition yields:

$$
P^{\prime}(\sigma)=\frac{g^{2} h^{2}\left(2 g h-3 g^{2}-\sigma(1-\sigma) h^{2}\right)(2 \sigma-1)}{\left[g^{2}-\sigma(1-\sigma) h^{2}\right]^{3}}=0
$$

The only solution is $\sigma=1 / 2$. Evaluating the second derivative at $\sigma=1 / 2$, we have:

$$
P^{\prime \prime}\left(\frac{1}{2}\right)=\frac{32 g^{2} h^{2}(h-6 g)}{(h-2 g)^{2}(2 g+h)^{3}}
$$

This expression is negative for $g>h$. Thus, $\sigma=1 / 2$ is a local maximum. Since it is the unique stationary point and functions are differentiable, we can infer that this is also the global maximum. 


\section{FIGURES}

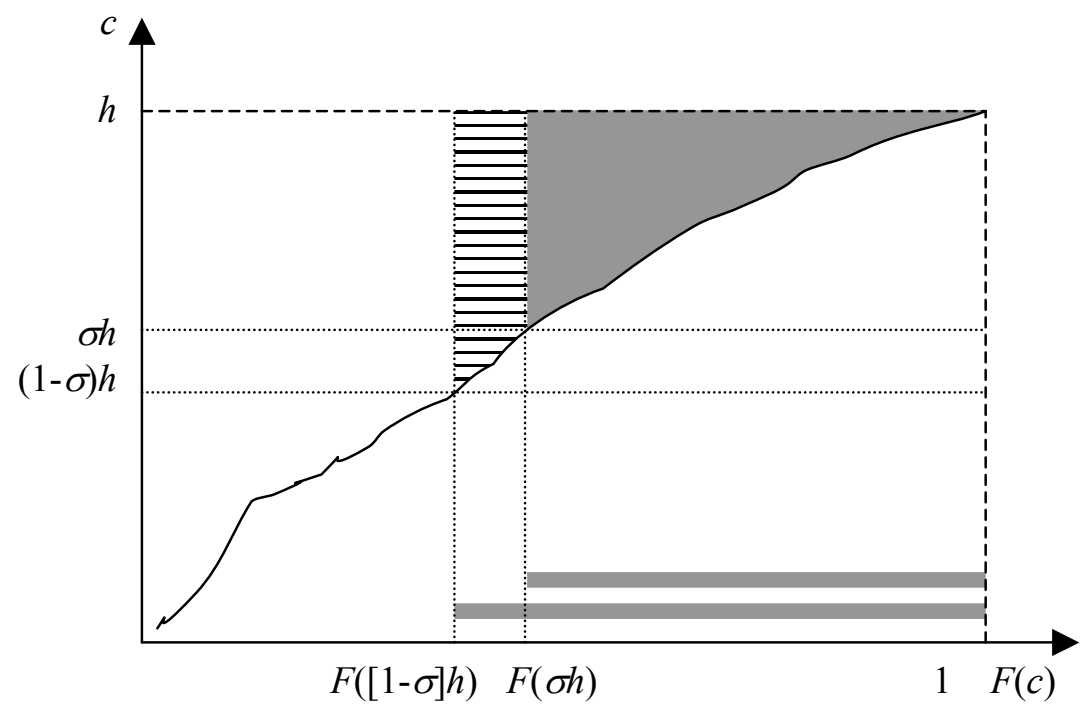

Figure 1 - Social cost and probability of accidents under a sharing rule

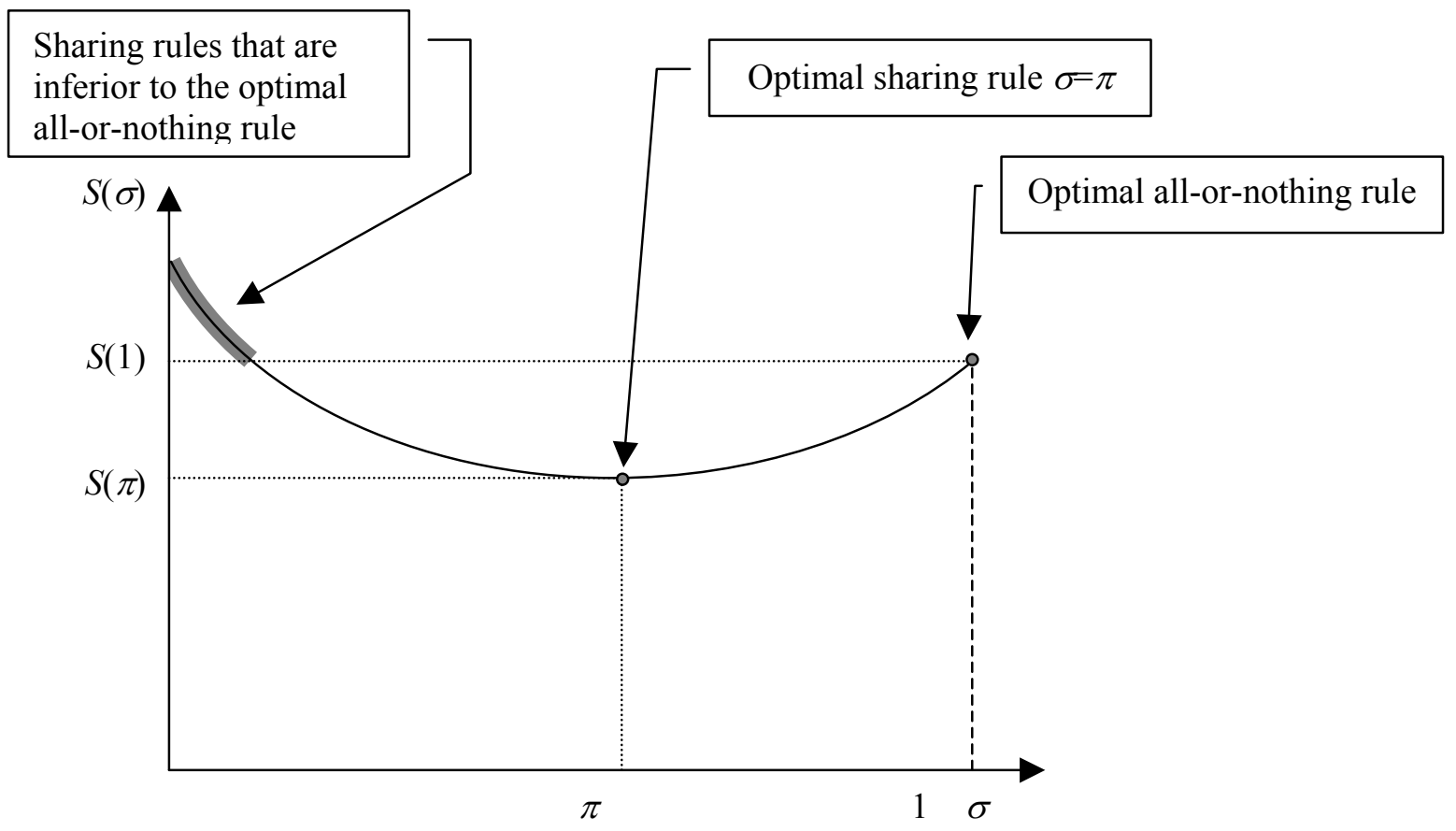

Figure 2 - Social cost as a function of the liability rule for uniform distributions and $\pi>1 / 2$ 


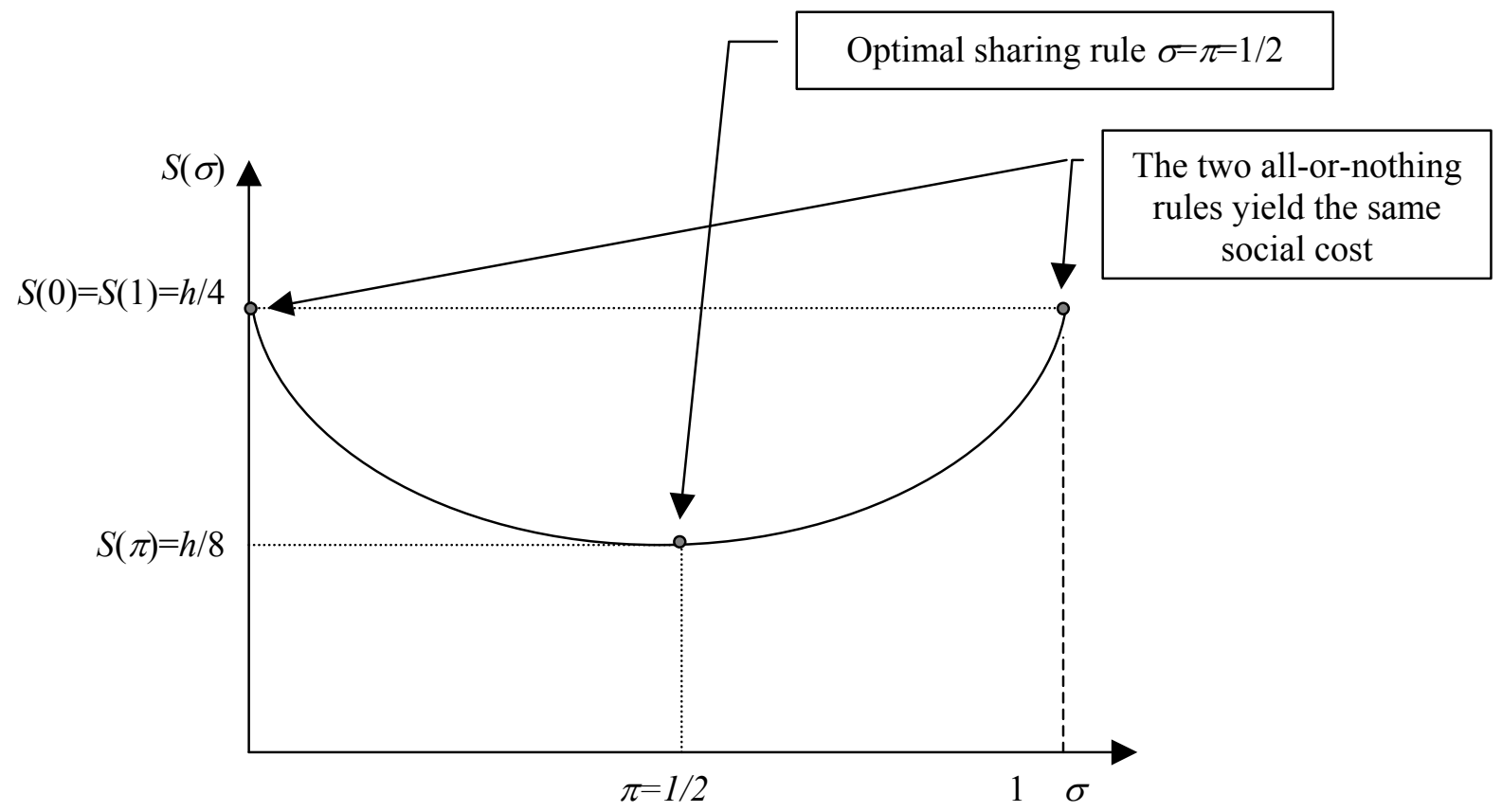

Figure 3 - Social cost as a function of the liability rule for uniform distributions and $\pi=1 / 2$

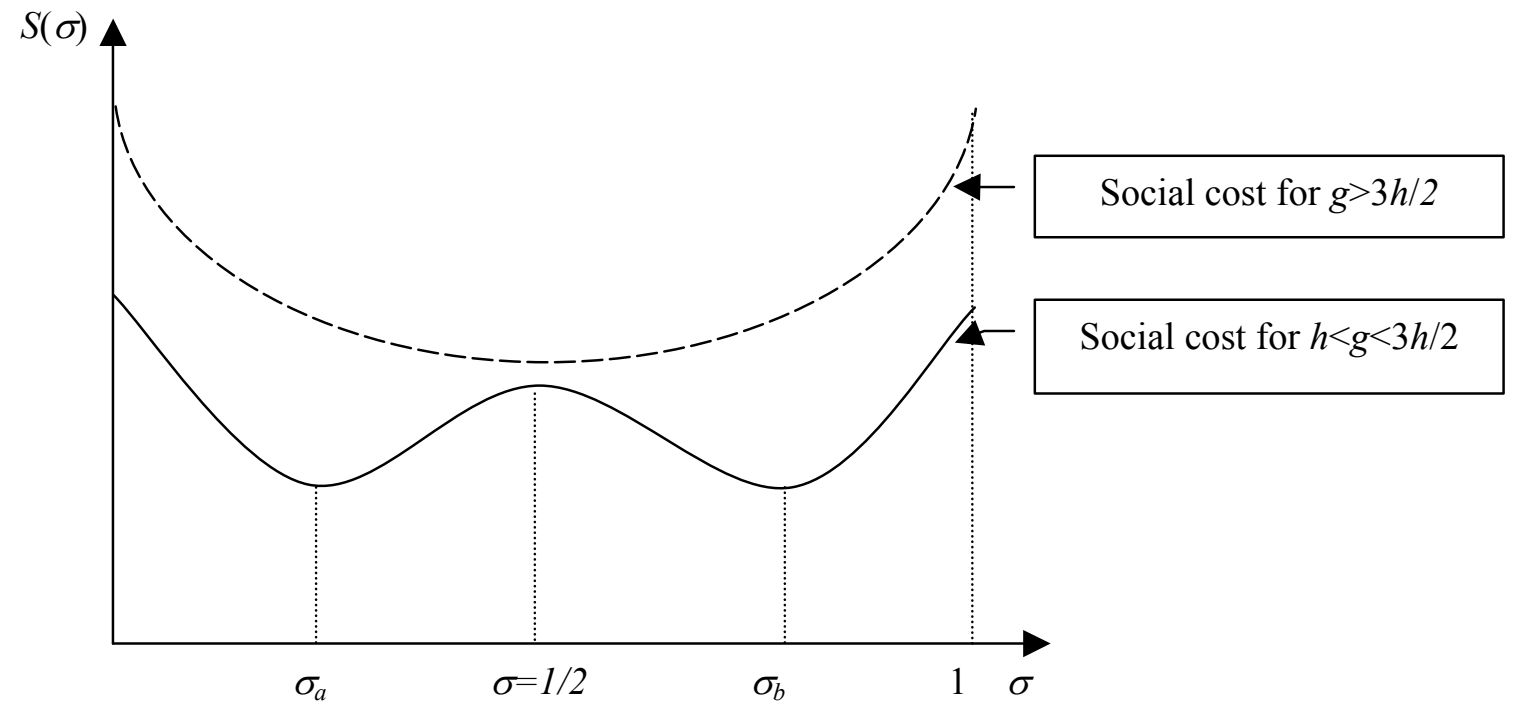

Figure 4-Social cost in alternative-care cases for uniform distributions 